\title{
HighNyammer: Metrics Feedback on BBS for Collabora- tive Improvement of Collective Cognitive Responsibilities
}

\author{
Hideki Kondo *, Sayaka Tohyama ${ }^{\dagger}$, \\ Ayano Ohsaki *, Masayuki Yamada *
}

\begin{abstract}
This study aimed to examine whether real-time feedback can enhance "collective cognitive responsibility" as contribution from each learner's collective cognitive responsibility is essential in collaborative knowledge creation. To this end, we hypothesized that higher values of betweenness centrality in subjects' relationships reflect an improvement in collective cognitive responsibility, and developed a bulletin board system (BBS) for feeding back values of betweenness centrality in real time to know one's position within the community using network-analysis methodology. The research target was a student-staff community working for "Classroom-M" that used the BBS developed by us, called "HighNyammer," for information-sharing among students and staff members. HighNyammer revealed the real-time value of betweenness centrality for each participant based on the relationships between the authors of posted articles. We conducted questionnaire surveys and retrospective interviews with four student-staff members to evaluate the function of HighNyammer. The subjects demonstrated the potential effectiveness of this function, especially for novice workers. Furthermore, they recognized the meaning of betweenness centrality value in relation to their own work as student-staff members. They also recognized that the meaning of betweenness centrality value depended on each student-staff member's degree of expertise in Classroom-M.
\end{abstract}

Keywords: BBS, collective cognitive responsibility, real-time feedback, social network analysis (SNA).

\section{Introduction}

It is well known that contribution of each learner's "collective cognitive responsibility" is essential in collaborative knowledge creation [1]. Collective cognitive responsibility is the disposition of each participant's responsible attitudes expressed during collaborative, rather than individual, problem solving. Zhang, Scardamalia, Reeve, and Messina [2] have suggested that

\footnotetext{
Kyushu Institute of Technology, Fukuoka, Japan

Shizuoka University, Hamamatsu, Japan

* Advanced Institute for Industrial Technology, Tokyo, Japan
} 
collective cognitive responsibility can be examined using social-network analysis (SNA) [3][4] in a computer-supported collaborative learning (CSCL) environment. SNA is effective in revealing state changes in collaborative learning based on time series [5].

In SNA, metrics of betweenness centrality, degree centrality, and closeness centrality are used to reveal the transformation of individual relationships from the viewpoint of collective cognitive responsibility [6][7]. Value of betweenness centrality can illustrate the importance of each participant node as a mediator in a community. Each node's value reflects the distributed engagement of the participants. Zhang, Scardamalia, Reeve, and Messina [2] conducted an analysis after completing practice sessions because the analysis required a complete set of CSCL discourse. The participants had to be unaware of their position in the community; only the researchers can examine how to enhance each participant's activity after a class concludes. This setup can cause problems when participants try to improve their activities. The present study examined the effects of quantitative real-time feedback for participants to enhance their self-directive activities in the community.

\section{Purpose}

This research examined the extent to which real-time feedback can enhance collective cognitive responsibility. We hypothesized that higher values of betweenness centrality in subjects' relationships reflect an improvement in collective cognitive responsibility. We therefore developed a bulletin board system (BBS) called "HighNyammer" and used the connections between articles posted on the BBS by participants working together in a community to calculate each participant's betweenness centrality. The scaffold was designed to help participants recognize their position within the community. We expected each participant in the target community to use these metrics to examine such questions as "What should I do?" and "How should I work?" during his/her work and exchange information through discussion with peers.

\section{Research Background}

\subsection{Community of Learners}

In recent years, skillsets which all people are expected to have are being redefined to design future educational environment. One of the points being focused in these skillsets is collaborative work or collaborative learning. People in the $21^{\text {st }}$ century are expected to enhance their skill of collaboration [8] because doing something collaboratively generally leads to better results than doing it individually [9], especially in a complicated-problem solving environment. On the other hand, knowledge which we once acquire is expected to be transferrable one [10][11]. Learning environment works as a base to improve our collaboration skills and acquire transferable knowledge. The concept of "adaptive experts" [12][13] is one of the most appropriate for designing learning environments with the above-mentioned characteristics.

In contrast to "routine experts," adaptive experts are those for whom "it is possible to invent new procedures from their specialized knowledge." Bransford, Brown, and Cocking [14] argued the importance of developing students' self-directive attitudes in learning from the viewpoint of adaptive expertise because students can transfer their knowledge or skill to other domain's learning. Scardamalia and Bereiter [15] demonstrated the importance of the attitude of being responsible for creating one's knowledge in social interaction, and Miyake [11] suggested that 
students who were in such learning situations achieved adaptive expertise. Darling-Hammond and Baratz-Snowden [16] emphasized the importance of adaptive expertise in teachers' development. Teachers, as experts, are expected to develop brand-new teaching methods when their routine work is inefficient.

The characteristics for development of adaptive expertise defined by Hatano and Inagaki [12][13] are: (1) Continuously encounter various novel challenges; (2) Engage in dialogical interactions; (3) Be relieved from imminent requirements; and (4) Be in a community respecting understanding of the whole system. These characteristics can be widely adopted to design new learning environment.

"Knowledge creation" is expected to occur in a well-functioning adaptive-expertise environment. Knowledge creation is the ability to create new knowledge, expand it to the whole organization, and solidify it as products, services, and systems [17]. Zhang, Scardamalia, Reeve, and Messina [2] analyzed discourse in a CSCL environment to examine students' development as active agents in knowledge creation from viewpoints of "awareness of contributions," "complementary contributions," and "distributed engagement."

\subsection{Collective Cognitive Responsibility}

Collaborating with one's peers seems to require specific collaboration skills. Collective cognitive responsibility can be described as a state in which individuals within an organization understand each other's knowledge; it is also a state of mutual review in which each participant feels responsible for organizational knowledge [1][18]. Contribution from each learner's collective cognitive responsibility is essential in collaborative knowledge creation [7]. However, it is difficult to observe improvement in collective cognitive responsibility because it is treated like a general skill for broader working situations and not as a discipline or concrete knowledge.

Zhang, Scardamalia, Reeve, and Messina [2] investigated the effects of learning changes within a learning format by carrying out a study of the characteristics of light in a fourth-year elementary-school class over three years. The first year involved division-of-labor-style collaborative learning in fixed groups; the second year involved collaborative learning that employed strategies such as jigsaw learning, where groups interacted while being reconfigured; and the third year involved collaborative learning that allowed learners to independently form and rearrange groups and formulate inquiries that reflected their own individual interests under the shared theme of "light."

The study combined face-to-face discussions with data drawn from an SNA-based CSCL environment ("Knowledge Forum" [19]). Each participant was treated as one node and analyzed in relation to student viewing, citation logs, and teacher notes. The results visualized in graph form revealed that first-year students generally viewed and cited their own notes and those of group members, while the teacher "connected" the groups by viewing and citing all their notes. In the second year, students interacted among groups and independently viewed and cited the notes of various groups; however, the "center" of all interactions remained the teacher. The third-year students, given the freedom to create and rearrange their own groups, proactively viewed and cited each other's notes within the class. For the first time, the teacher was removed from the central position. In line with the increased vitality of interactions, the students' understanding of the content was deeper in the third year than in the first or second year. 


\subsection{SNA}

SNA enables the data-based visualization of changes involving nodal interactions [3][4]. Each node's meaning changes depending on the target dataset. For example, nodes can represent members who belong to the same community or articles written for a specific BBS. In the context of SNA, metrics of betweenness centrality, degree centrality, and closeness centrality are traditionally used to reveal the transformation of individual relationships [6][7].

SNA is the ideas applied to educational contexts to externalize relationships between the students or words using discourse as data and the analytical method [2][5][7]. It enables the automated data-based visualization of changes in the ways people interact and analysis of the interaction between participants and time-based changes. Oshima, Oshima, and Matsuzawa [5] used KBDeX for group work in a physics class to show the significant influence of the teaching assistants' (TAs) oral communications on the quality of the oral communications of groups from the viewpoint of knowledge creation. Using SNA, Zhang, Scardamalia, Reeve, and Messina [2] found an increase in students' degree centrality and betweenness centrality in classrooms designed to improve students' collective cognitive responsibility in knowledge creation activity. This study showed that it is possible to investigate collective cognitive responsibility by calculating the degree of centrality and betweenness centrality of such interactions.

Recently, a new analytical method based on network analysis was used instead of SNA. Csanadi, Eagan, Kollar, Shaffer, and Fischer [20] used "epistemic network analysis," which models temporal co-occurrences of codes in discourse based on the theory of "epistemic frames" [21]. However, no previous research that uses this analysis shows improvement in collective cognitive responsibility. Therefore, we chose traditional SNA in our study.

\subsection{Feedback to Learners}

The above-mentioned studies suggested that students' data-collecting and scaffold tool play an essential role in evaluation. van Aalst [22] reported the importance of providing these tools to learners, how to use them in classrooms, and how to interpret the data saved by these tools. This suggests a strong relationship between students' learning activities and data use for students' assessment.

From the point of view of socially shared regulation of learning [23], data which was saved by students who used tools can be used to give feedback to the students. However, it is difficult to create feedback data using students' learning activities in tools when we only have qualitative analysis method for trained researchers. If we analyzed the data by qualitative analysis (such as coding-and-counting analysis [24]) and then analyze the results using SNA, the feedback to students is delayed. On the other hand, simple numeric results such as the number of articles posted by a student on BBS or the numbers of characters in one's posted article should be carefully treated if they are to be used as feedback to students because it is not easy to interpret these results. There is a risk of misleading the students about the characteristics of an "ideal" learner. For example, how to detect whether learners encounter novel challenges from the adaptive expertise [12][13] point of view. Thus, it is not easy to provide real-time feedback using learners' learning data because of the difficulty in pre-defining all keywords which show "this is a novel challenge situation." 


\section{Research Target}

\subsection{Target Facility}

We selected a student-staff community that worked for "Classroom-M" as our research target. Built in 2011, Classroom-M is an active-learning classroom in a university that offers classes in information systems [25]. It has a floor area of $260 \mathrm{~m}^{2}$ and a seating capacity of 90 students. The facility is designed for group work requiring ICT equipment and is used for a wide range of classes, from first-year undergraduate courses to postgraduate study, carried out in a flexible manner (Figure 1).

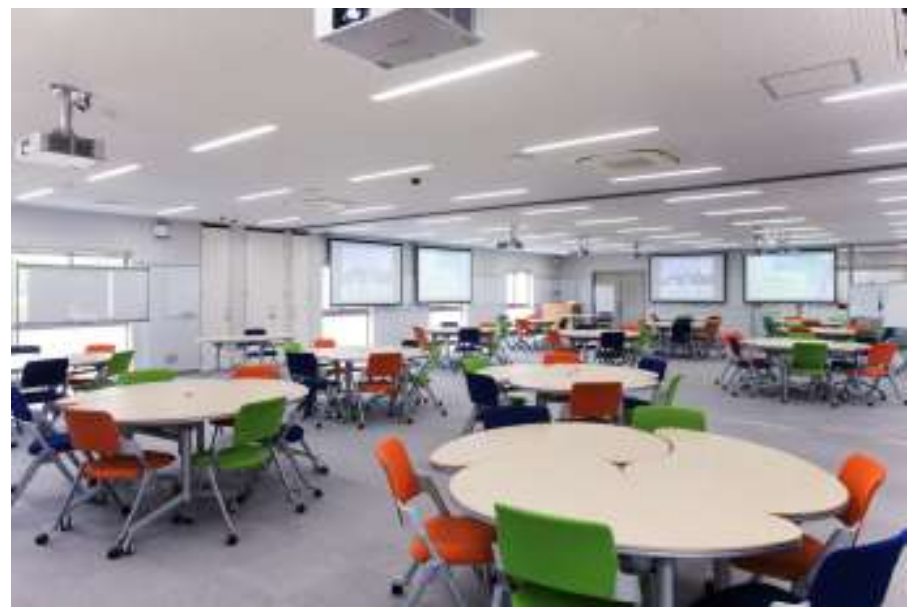

Figure 1: Interior of Classroom-M

To support classes in information systems, Classroom-M is equipped with 100 laptop computers and 60 tablets, all centrally managed and able to operate simultaneously over a wireless LAN. From its completion in 2011 to 2018, it has maintained an extremely high level of operation, with a maximum occupancy of $84 \%$; in fact, the rate of occupancy has never dropped below $60 \%$.

Classroom-M is staffed by one instructor, one support-staff member, and 5-15 student-staff members, all of whom make up the operational team for this facility. Instructors affiliated with Classroom-M are stationed in the staff room, with student-staff members to support them. The instructor and the support-staff member promote problem solving by encouraging discussions between the student-staff members. However, they provide direct instruction on how to solve the problems if the student-staff members cannot solve them.

\subsection{Tasks of Student-Staff Members}

Student-staff members are responsible for improving the overall learning environment of Classroom-M; they also support students and teachers who use Classroom-M for specific classes or after-class activities. The student-staff members work in shifts as part-time workers; they do not work simultaneously. Applicants for student-staff jobs are selected from across school years and major subjects. Student-staff members' work differs from university TAs because their main task, in a broader sense, is to promote continuous improvement in the Classroom-M learning environment. They support all classes held in Classroom-M, not just specific classes. Student-staff members perform the following main two tasks. 


\subsubsection{Improving the Equipment}

Student-staff members follow the principle of "continuously re-creating an improved learning environment." They are expected to improve equipment, including laptop computers and e-learning systems. They must continuously survey new technologies and gadgets and introduce them into the Classroom-M learning environment. They are also responsible for maintaining the infrastructure, verifying operations, updating software, exchanging faulty equipment, and organizing replacements. Student-staff members must have a deep understanding of every operation because all the systems and pieces of equipment are interrelated and function simultaneously.

\subsubsection{User Support}

During classroom hours, in addition to following the instructors' directions, student-staff members proactively cooperate and consult with all instructors and users to support classroom usage. A typical task might involve setting up a specific class environment and providing in-class support. Student-staff members do not follow a fixed or predetermined work structure. Instead of remembering a certain way of doing things, they are expected to understand and share each instructor's intentions and work independently.

Each task requires highly specialized knowledge and techniques and includes implementation challenges requiring preparation to meet expectations. Student-staff members need to: (1) work collaboratively, share information, and arrive at new solutions through discussion; and (2) study theories of educational technologies and learning sciences, acquiring sufficient expertise to design both empirically- and theoretically-supported learning environments.

Continuous problem defining by student-staff members in real situation is essential for authentic problem solving which encourages them to create new solutions consisting of various types of knowledge and techniques. The variety of knowledge and techniques are shared by student-staff members in relation to each student-staff's majors or interests except for knowledge and technique which are required for every student-staff's daily work in classroom-M. Basically, it is too difficult to both define problems and solve problems in authenticity alone; discussion with peers to share various viewpoints, knowledge, and technique is expected to occur in such situations. Of course, if problems are easy to solve alone, discussions may not occur, and student-staff members may lost chances to share their knowledge or technique. We think the problem-defining and problem-solving situations which require student-staff member's discussions for sharing knowledge or technique constantly are key for student-staff's development of collective cognitive responsibility.

\subsection{BBS}

Student-staff members post and read articles on their BBS. The BBS is used to announce updates and problems, request help in solving tasks, share daily reports from each student-staff member, and help members accomplish similar goals. It has been in continuous use since 2012 and has spooled around 40,000 articles. Since the start of student-staff recruiting, 60 registered users have relied on the BBS. Those who have finished working as student-staff members (almost all graduates) can continue to write and read articles; however, they can post articles only when external help is requested. 


\section{HIGHNYAMMER}

\subsection{Main Function}

In our study, we designed a special BBS named HighNyammer that shows the value of betweenness centrality for each student-staff member based on posted articles. A previous study that specially focused on the value of betweenness centrality was Oshima, Niihara, Ota, and Oshima [26]. It suggested that the value of betweenness centrality of some utterances in discussions radically changed between several phases. HighNyammer was developed to help student-staff members carry out their tasks in Classroom-M. Figure 2 is a screenshot of HighNyammer; the value of betweenness centrality is shown in the red box.

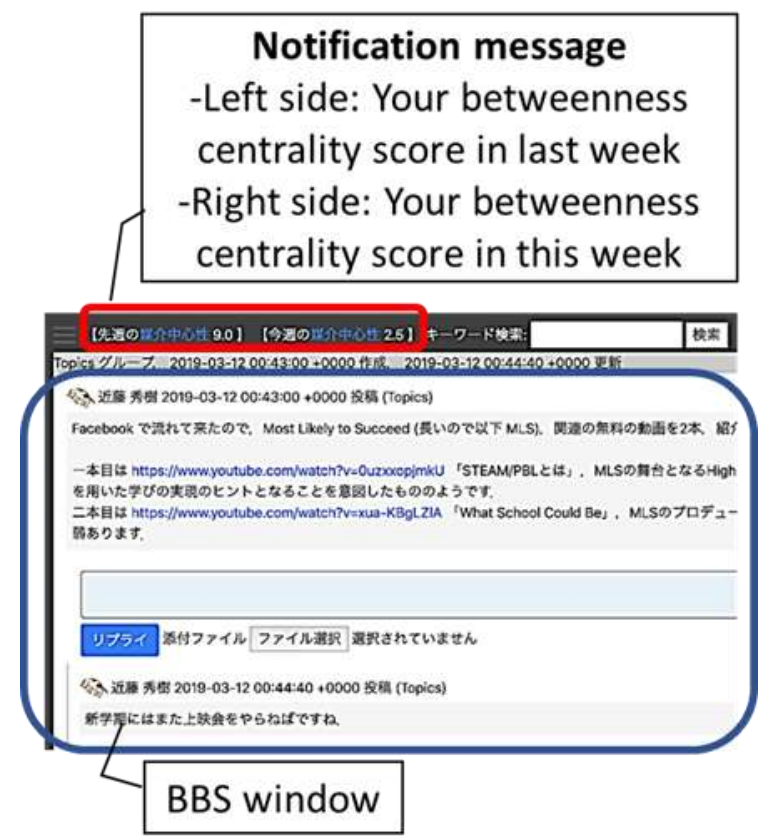

Figure 2: Screenshot of HighNyammer

The values of betweenness centrality are calculated using the average value of last week and this week. The value of this week changes on a real-time basis, depending on the number of articles posted and links made. For comparison, the value of last week is provided. The betweenness-centrality values are shown only to logged-in users. Student-staff members can use their own betweenness-centrality values to reflect on their activities in Classroom-M. We built HighNyammer using Ruby on Rails 5.2, PostgreSQL 10.6, and Neo4j 3.5.3, which is a graph database management system [27]. The whole system works on Ubuntu 18.04.2. We selected Amazon Lightsail (4GB RAM, 2 vCPU, 80GB SSD) as a platform to provide a stable service.

\subsection{Focused Metrics}

As mentioned above, student-staff members in classroom-M are expected to exchange knowledge and technique in their discussion on problem-defining or problem-solving. Therefore, we focused on value of betweenness centrality because it shows the frequency of exchanging information between nodes. Values of betweenness centrality illustrate the importance of each participant node as a community mediator. A higher betweenness-centrality value for a 
specific node means that a participant mediates effectively between other participants by referring to (or being cited by) their articles. A lower betweenness-centrality value means that the participant posts articles independently, without referring to or being cited by other participants' articles. The formula to calculate node i's value of betweenness centrality is as follows:

$$
C_{i}=\sum s \neq t \neq i \quad \frac{\sigma_{s, t}(i)}{\sigma_{s, t}}
$$

Note that $\sigma(\mathrm{s}, \mathrm{t})(\mathrm{i})$ is the number of routes that are intermediated by node i out of the shortest route between node $\mathrm{s}$ and node $\mathrm{t}$.

\subsection{Calculation of Betweenness Centrality}

In HighNyammer, it is possible to post either a "1st post," which has no parental posts, or a "reply post," which is the child of the 1st post. If all 1st posts have reply posts, the structure of posts in HighNyammer looks like a tree, as shown in Figure 3. The gray circles highlight groups and threads associated with posts in HighNyammer. A group consists of the main categories of discussion themes; each group can contain multiple threads. A thread comprises subthemes within each group. Each thread has a unique thread ID; a 1st post and all reply posts associated with that 1st post have the same thread ID. 1st posts and reply posts are shown as black circles. The 1st post and reply posts include information about the body (content), author, post-date, parental relations between posts, and thread ID. The characters within the black circles indicate the author(s) of each post.

Each post is treated as a node from a network-analysis viewpoint. To calculate the betweenness centrality value of each author, HighNyammer processes the information as follows:

(1) It extracts nodes with the same thread ID in a given week.

(2) It detects the authors of each node in (1).

(3) It creates a sub-social network based on the author's name using (2).

(4) It repeats steps (1) to (3) for all thread IDs.

(5) It calculates each author's betweenness centrality, using all aspects of the sub-social network, apart from replies posted by the author of the 1st post.

The sub-social network of Figure 3 is shown as Figure 4. Note that the edges between A and B in Figure 4 are studiously drawn with multiple lines to show the density of the relationship. The calculated values of betweenness centrality were unweighted. To speed up the calculation, HighNyammer used a library function to calculate the values of betweenness centrality (The function was provided by $\mathrm{Neo} 4 \mathrm{j}$ ). 


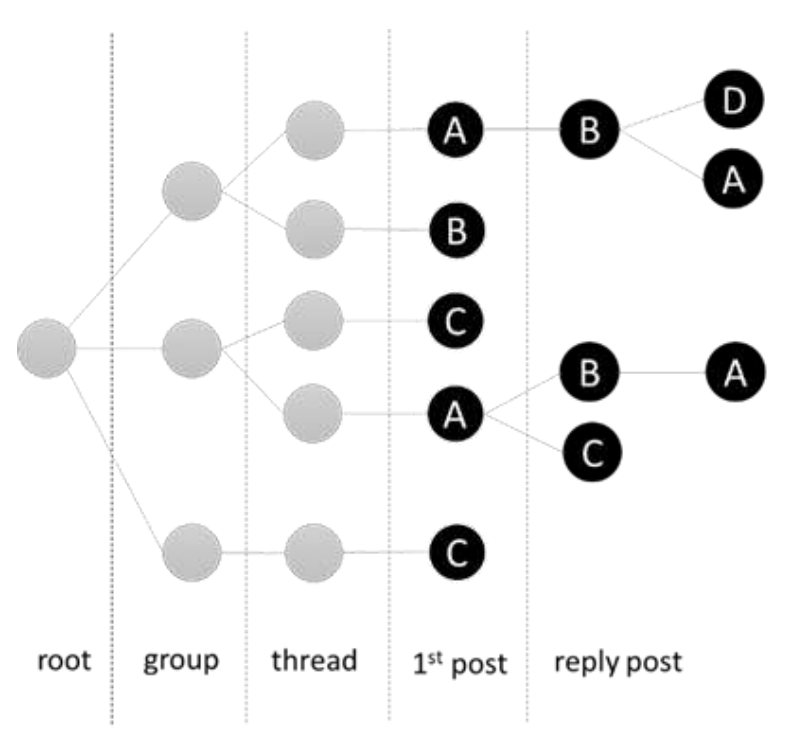

Figure 3: Structure of articles in HighNyammer

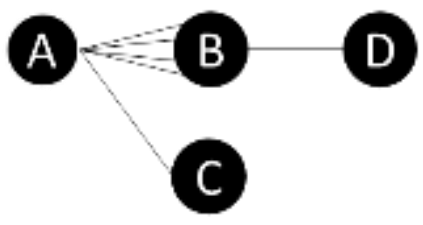

Figure 4: The sub-social network of Figure 3 created by authors

\subsection{Why Calculate Betweenness Centrality without Considering Content}

HighNyammer provides a new and simple form of scaffolding to improve each participants' reflections. The above-mentioned calculation methodology completely ignores content; it only checks the relationships between authors. Thus, posts that provide rich information (e.g., explanations of system errors) and maintain social relations (e.g., "Thanks") get treated equally. We hypothesized that real-time simple feedback would be essential; establishment of an automatic calculation method of the participant's position in a community is critical for the accuracy of the positions because actual contents or activities must be reviewed by each student-staff member anyway. Another reason is that Zhang, Scardamalia, Reeve, and Messina [2] adopted the same methodology in their research; they counted numbers of note-reading, links between notes, and cliques each student belonged to, and then calculated the centrality of each participant before checking content of each node.

\section{Evaluation Method and Expected Results}

\subsection{Overview}

To evaluate the effect of HighNyammer, we planned an initial and a delayed questionnaire-survey of student-staff members and then compared their results. The purpose of the initial questionnaire-survey was to know each student-staff member's initial feeling toward HighNyammer. The delayed survey was conducted about ten months after the initial survey. Along 
with the delayed survey, we also conducted retrospective interviews of the student-staff members. The purpose of these surveys and the interview was to ascertain whether showing betweenness centrality values to student-staff members would influence their activities.

The attributes of the four student-staff members we selected as the subjects are shown in Table 1. $\mathrm{A}$ and $\mathrm{B}$ had been student-staff members for less time than $\mathrm{C}$ and $\mathrm{D}$, who were relative experts, according to the Classroom-M instructor. The subjects used HighNyammer for two months (1/6/2019-3/13/2019) before the survey, and continued the trial use till 1/10/2020. The retrospective interview was conducted between $1 / 11 / 2020$ to $1 / 12 / 2020$. It took an average of about thirty minutes per person to conduct the interview. The subjects had used HighNyammer without the betweenness-centrality-feedback function for six months (4/29/2018-1/5/2019) before using it with the betweenness-centrality-feedback function.

Table 1: Subject Attributes (in January 2020)

\begin{tabular}{clc}
\hline Name & Grade & Total Service Years in Classroom-M \\
\hline A & Junior & 2.5 years \\
\hline B & Senior & 2.5 years \\
\hline C & Senior & 4 years \\
\hline D & Second year master's student & 5 years \\
\hline
\end{tabular}

In the trial use, student-staff members were encouraged to post articles on HighNyammer on a daily basis and share their work in Classroom-M. An explanation of the trial which also appeared on HighNyammer is shown in Figure 5. The explanation advised participants to "please try to attain a higher betweenness centrality value on HighNyammer." The student-staff members were not provided additional information about the betweenness centrality values shown on HighNyammer or given any instruction.

\begin{abstract}
$\mathrm{Hi}$,
A new function (HighNyammer) has been added to this system (BBS). With this function, the system automatically calculates the value of betweenness centrality for each person. This value reflects some aspects of collaborative working attitudes within the team. If you add new information to another person's posts or receive comments from others, the value will change. Please try to work with this system to attain higher values.

Please note, when you interpret values, a higher value does not always indicate a "better" situation. For example, if one student-staff member earns higher values while other staff members receive lower values, the situation may not be good. If all student-staff members receive similarly low values, the situation is not good. Please try to read other student-staff members' posts carefully with attention. All colleagues should aim to support each other regularly on this system.
\end{abstract}

Figure 5: Instructions for the trial (the original version was written in Japanese)

\title{
6.2 Questionnaire Survey
}

The initial and the delayed survey were conducted using an online form. The questionnaire included ten questions as shown in Table 2. Before the questionnaire, we asked the student-staff members whether they noticed the metrics-feedback function. 
Table 2: Questions and Answering Options in Questionnaire Survey

\begin{tabular}{|c|c|}
\hline Questions & Answering Options \\
\hline Q1. How often do you visit HighNyammer? & $\begin{array}{l}\text { 1. Every day } \\
\text { 2. About 3-4 days a week } \\
\text { 3. About once a week } \\
\text { 4. Several times a month } \\
\text { 5. Other (please explain) } \\
\end{array}$ \\
\hline $\begin{array}{l}\text { Q2. How often do you check your be- } \\
\text { tweenness-centrality values on High- } \\
\text { Nyammer? }\end{array}$ & $\begin{array}{l}\text { 1. Every time I visit } \\
\text { 2. About once every three times } \\
\text { 3. About once every six or seven times } \\
\text { 4. Never } \\
\text { 5. Other (please explain) }\end{array}$ \\
\hline $\begin{array}{l}\text { Q3. Please describe how you respond to } \\
\text { your betweenness-centrality value. }\end{array}$ & $\begin{array}{l}\text { 1. I try to attain a higher value. } \\
\text { 2. I try to attain a lower value. } \\
\text { 3. I do not try to change the value. } \\
\text { 4. Other (please explain) }\end{array}$ \\
\hline $\begin{array}{l}\text { Q4. This question is only for those who have } \\
\text { tried to attain a higher or lower value. } \\
\text { What did you do to change the value? }\end{array}$ & (free description) \\
\hline $\begin{array}{l}\text { Q5. This question is only for those who have } \\
\text { tried to attain a higher or lower value. } \\
\text { How did the value change because of } \\
\text { your activity? }\end{array}$ & $\begin{array}{l}\text { 1. The value increased. } \\
\text { 2. The value did not change. } \\
\text { 3. The value decreased. } \\
\text { 4. Other (please explain) }\end{array}$ \\
\hline $\begin{array}{l}\text { Q6. This question is only for those who have } \\
\text { tried to attain a higher or lower value. } \\
\text { Why did you try to attain a higher or } \\
\text { lower value? }\end{array}$ & (free description) \\
\hline $\begin{array}{l}\text { Q7. This question is only for those who have } \\
\text { tried to attain a higher or lower value. } \\
\text { Can you continue your activities to attain } \\
\text { a higher or lower value? }\end{array}$ & $\begin{array}{l}\text { 1. Yes, I undertook these activities before I } \\
\text { was aware of the betweenness-centrality } \\
\text { function, and I am continuing these ac- } \\
\text { tivities now. } \\
\text { 2. Yes, I will probably continue because I } \\
\text { have become accustomed to do such ac- } \\
\text { tivities. } \\
\text { 3. Yes, I may be able to continue doing such } \\
\text { activities while paying attention to the } \\
\text { value of betweenness centrality. } \\
\text { 4. No, it may be difficult to continue with- } \\
\text { out paying attention to the value of be- } \\
\text { tweenness centrality. } \\
\text { 5. Other (please explain) }\end{array}$ \\
\hline $\begin{array}{l}\text { Q8. Please explain how you interpret the } \\
\text { value of betweenness centrality on } \\
\text { HighNyammer. }\end{array}$ & (free description) \\
\hline
\end{tabular}




\subsection{Retrospective Interview}

In the retrospective interview, second author worked as an interviewer. The student-staff members knew the interviewer and her research interest because she had been regularly visiting Classroom-M once a half-year on an average since 2012 to conduct research meetings with the first author. She has experience of conducting interviews of graduate student-staff members in Classroom-M to examine how they grew up in their working community. The questions asked in the retrospective interview are shown in Table 3. Based on the philosophy of retrospective interviews, the interviewer slightly changed the sentences and orders of these questions depending on each interview's situation.

Table 3: Questions of Retrospective Interview

\begin{tabular}{ll}
\hline No. & Questions \\
\hline Q1 & $\begin{array}{l}\text { Can you explain or draw relationships between all the student-staff members? Does it } \\
\text { differ from the ideal one? }\end{array}$ \\
\hline Q2 & Do you have any messages for student-staff members who worked less time than you? \\
\hline Q3 & $\begin{array}{l}\text { Do you feel any inconvenience because of the externalization of these between- } \\
\text { ness-centrality values? }\end{array}$ \\
\hline
\end{tabular}

\subsection{Expected Results}

We expected the student-staff members to change their activities on HighNyammer based on the values of betweenness centrality - particularly in the case of student-staff members who had only short-term experience in Classroom-M. We also expected student-staff members who changed their activities on HighNyammer to change in ways similar to those found in the study by Zhang, Scardamalia, Reeve, and Messina [2], such as awareness of contributions, complementary contributions, and distributed engagement. In particular, we anticipated that they would try to read and respond to their colleagues' posts, and make decisions or plans for their community. However, expert student-staff members could do the above-mentioned activities without suggestion of his/her value of betweenness centrality because they had already learned the value of such activities, as scaffolded by the Classroom-M working environment.

\section{Results and Discussion}

\subsection{Overview of the Questionnaire Survey}

All the student-staff members who answered the questionnaire had noticed the newer-implementation of metrics-feedback function. Table 4 shows the answers to the questions in the questionnaire. It is clear from these results that all the student-staff members habitually visited HighNyammer once a day (Q1), and checked their own values at least twice a week (Q2) both in the initial and delayed survey phase. Only student-staff member D never tried to earn higher value of betweenness centrality. First, we focus below on the other three student-staff members. 


\subsection{Student-Staff Members Who Tried to Get Higher Values}

\subsubsection{Activity Change}

Three of the four student-staff members (A, B, and C) tried to earn higher values (Q3) in the initial phase. According to their detailed answers to Q4, B and C tried to communicate with their colleagues by posting replies and comments. A strengthened his attitude to post replies to his colleagues in the delayed phase than the initial phase. It is noteworthy that B prompted replies from his colleagues and C carefully read his colleagues' posts in the delayed phase. These results suggest that all the three student-staff members, especially B and C, strengthened their attitudes to communicate with their colleagues on HighNyammer in the delayed phase than the initial phase.

\subsubsection{Attitude Change}

From the answers to Q5, it was found that A and B succeeded in attaining higher value of betweenness centrality in the delayed phase although they failed to do that in the initial phase. Only $\mathrm{C}$ succeeded in getting higher value in the initial phase and kept on getting it in the delayed phase. How they understood the meaning of the value of betweenness centrality was shown in the answers to Q6: they were naive in the initial phase. A and C understood the value of betweenness centrality as activeness of each student-staff member or the degree of participation and B might not have any specific idea about the value of betweenness centrality. In the delayed phase, $\mathrm{C}$ might have drastically changed his idea because he referred to the importance of collaboration in Classroom-M. It suggested that $\mathrm{C}$ tacitly knew what was needed to attain higher value in the initial phase, and eventually he understood what was needed to get higher value and what activities were improved when he tried to get higher values. A and B slightly changed their attitudes from caring about the betweenness centrality values to not caring except when they had "zero" value. Both A and B paid too much attention to change the values in the initial phase; however, they created a comfortable mental distance from the values in the delayed phase.

The drastic change in attitude of $\mathrm{C}$ can be seen from his answer to Q7. His answer in the delayed phase was "I can continue" although his answer at the initial phase was "difficult to continue" doing activities to get higher values. It suggested that $\mathrm{C}$ was becoming natural in doing activities which increased value of betweenness centrality without paying any special attention which he once paid in the initial phase. In contrast, A did not change his answer to Q7 between the initial and the delayed phase, while B changed his answer to "difficult to continue" doing activities which increase the value of betweenness centrality. These results suggested that A and B did not accustom to the values and need to pay special attention to do activities which increase the value of betweenness centrality.

\subsection{Changes in Understanding of Betweenness Centrality Value}

Student-staff member D who never tried to increase his betweenness-centrality value changed his idea more concretely using the word "correctly" in the delayed phase because he used only the word "contribution" in the initial phase. From these results, he interpreted the meaning of the value of betweenness centrality as an indicator of correctness of the work as student-staff in Classroom-M. It reflects the ideal situation of activities of student-staff members because they are expected to solve problems through collaboration with each other as mentioned in research target section. Similar answer was shown in the delayed phase of C; he mentioned that the value 
of betweenness centrality reflected the "ideal" image of student-staff members in Classroom-M. Both $\mathrm{C}$ and $\mathrm{D}$ seemed to realize in the delayed phase that the value of betweenness centrality enhances ideal activities of student-staff members in Classroom-M.

In contrast, A and B simply explained the meaning of the value of betweenness centrality as a general mediation function in the delayed phase. They both already knew the basic meaning of values of betweenness centrality in the initial phase; however, they did not drastically change their idea between the initial and the delayed phase.

Table 4: Answers to the questionnaire (Answers were summarized, I: Initial, D: Delayed)

\begin{tabular}{|c|c|c|c|c|c|}
\hline No. & I/D & Student-Staff A & Student-Staff B & Student-Staff C & Student-Staff D \\
\hline \multirow{2}{*}{ Q1. } & I & 1 (every day) & 1 (every day) & 1 (every day) & 1 (every day) \\
\hline & $\mathrm{D}$ & 1 (every day) & 5 (only weekday) & 1 (every day) & 1 (every day) \\
\hline \multirow{2}{*}{ Q2. } & I & 1 (every time) & $\begin{array}{l}2 \text { (once in every } 3 \\
\text { times) }\end{array}$ & 1 (every time) & $\begin{array}{l}2 \text { (once in every } 3 \\
\text { times) }\end{array}$ \\
\hline & $\mathrm{D}$ & 1 (every time) & $\begin{array}{l}2 \text { (once in every } 3 \\
\text { times) }\end{array}$ & 1 (every time) & 1 (every time) \\
\hline \multirow{2}{*}{ Q3. } & I & $\begin{array}{l}1 \text { (try to get higher } \\
\text { value) }\end{array}$ & $\begin{array}{l}1 \text { (try to get higher } \\
\text { value) }\end{array}$ & $\begin{array}{l}1 \text { (try to get higher } \\
\text { value) }\end{array}$ & 3 (did not try) \\
\hline & $\mathrm{D}$ & $\begin{array}{l}1 \text { (try to get higher } \\
\text { value) }\end{array}$ & $\begin{array}{l}1 \text { (try to get higher } \\
\text { value) }\end{array}$ & $\begin{array}{l}1 \text { (try to get higher } \\
\text { value) }\end{array}$ & 3 (did not try) \\
\hline \multirow[b]{2}{*}{ Q4. } & I & $\begin{array}{l}\text { I posted my arti- } \\
\text { cles and tried to } \\
\text { reply to my col- } \\
\text { leagues' posts }\end{array}$ & $\begin{array}{l}\text { I posted my com- } \\
\text { ments to my col- } \\
\text { leagues' articles }\end{array}$ & $\begin{array}{l}\text { I tried to respond to } \\
\text { my colleagues' } \\
\text { posts }\end{array}$ & \\
\hline & $\mathrm{D}$ & $\begin{array}{l}\text { I posted my arti- } \\
\text { cles, and replied to } \\
\text { my colleagues }\end{array}$ & $\begin{array}{l}\text { I posted replies to } \\
\text { my colleagues and } \\
\text { welcomed their } \\
\text { replies to my arti- } \\
\text { cles }\end{array}$ & $\begin{array}{l}\text { I intentionally } \\
\text { posted replies to } \\
\text { my colleagues. So } \\
\text { I carefully read my } \\
\text { colleagues' posts }\end{array}$ & \\
\hline \multirow{2}{*}{ Q5. } & $\mathrm{I}$ & 2 (did not change) & 2 (did not change) & 1 (increased) & \\
\hline & $\mathrm{D}$ & 1 (increased) & 1 (increased) & 1 (increased) & \\
\hline \multirow{2}{*}{ Q6. } & I & $\begin{array}{l}\text { Because the visu- } \\
\text { alized value told } \\
\text { me that I was in- } \\
\text { active }\end{array}$ & $\begin{array}{l}\text { Because I wanted } \\
\text { to try attaining } \\
\text { higher value by my } \\
\text { posts }\end{array}$ & $\begin{array}{l}\text { Because I felt my } \\
\text { degree of partici- } \\
\text { pation was in- } \\
\text { creased when the } \\
\text { value increased }\end{array}$ & \\
\hline & $\mathrm{D}$ & $\begin{array}{l}\text { I felt I was inactive } \\
\text { when the value is } 0\end{array}$ & $\begin{array}{l}\text { I tried to attain } \\
\text { value because my } \\
\text { value was } 0 \text { for a } \\
\text { while }\end{array}$ & $\begin{array}{l}\text { To attain higher } \\
\text { value means col- } \\
\text { laboration with my } \\
\text { colleagues: it is } \\
\text { ideal activity for us }\end{array}$ & \\
\hline
\end{tabular}




\begin{tabular}{|c|c|c|c|c|c|}
\hline \multirow{2}{*}{ Q7. } & $\mathrm{I}$ & 3 (may continue) & 3 (may continue) & $\begin{array}{l}4 \text { (difficult to con- } \\
\text { tinue) }\end{array}$ & \\
\hline & $\mathrm{D}$ & 3 (may continue) & $\begin{array}{l}4 \text { (difficult to con- } \\
\text { tinue) }\end{array}$ & 2 (I can continue) & \\
\hline \multirow[t]{2}{*}{ Q8. } & I & $\begin{array}{l}\text { A degree of atti- } \\
\text { tude to activate this } \\
\text { community's ac- } \\
\text { tivities }\end{array}$ & $\begin{array}{l}\text { A value of how I } \\
\text { mediate commu- } \\
\text { nication among my } \\
\text { colleagues }\end{array}$ & $\begin{array}{l}\text { A simple value of } \\
\text { how I engage in } \\
\text { tasks as a stu- } \\
\text { dent-staff in this } \\
\text { community }\end{array}$ & $\begin{array}{l}\text { A simple value for } \\
\text { evaluation of each } \\
\text { student-staff's } \\
\text { contribution in this } \\
\text { community }\end{array}$ \\
\hline & D & $\begin{array}{l}\text { A degree of how I } \\
\text { involved my col- } \\
\text { leagues }\end{array}$ & $\begin{array}{l}\text { A value of how I } \\
\text { involved my col- } \\
\text { leagues as a com- } \\
\text { munity member }\end{array}$ & $\begin{array}{l}\text { A barometer of } \\
\text { how ideal stu- } \\
\text { dent-staff is in this } \\
\text { community }\end{array}$ & $\begin{array}{l}\text { A value of how I } \\
\text { correctly engaged } \\
\text { in this communi- } \\
\text { ty's work }\end{array}$ \\
\hline
\end{tabular}

\subsection{Retrospective Interview}

The answers to Q1 in the retrospective interview externalize the student-staff members' (A, B, C, and D) internal model of the relationship between all the student-staff members. Table 5 shows the drawn pictures of real and ideal relationships between student-staff members in Classroom-M as drawn by A, B, C, and D. Both B and D drew only one image because their idea of a real and an ideal relationship was same. However, B said that the number of arrows were different between the real and the ideal one: there were dense arrows in the ideal one. All the circles drawn by A, C, and D represented student-staff members and a teacher in Classroom-M (first author). The big circle drawn by B meant the common ground of the student-staff members and the teacher: Classroom-M and HighNyammer, and the small circles meant student-staff members and the teacher.

From these real images of relationships between student-staff members, all the four student-staff members drew ideal relationship images between all the members in Classroom-M using complete graph (A, C, and D) or star graph using the same width lines as the edges (B). In contrast, the real images in Table 5 differed from the ideal images in the answers except student-staff member B and D. A and C thought that there were some "core" members and the other members surrounded the core members.

A located older staff at the center and $\mathrm{C}$ located the teacher in Classroom-M at the center. Both of them hoped to change these situations into complete graphs which meant all the student-staff members and the teacher evenly collaborate with each other. B thought that there were some active members and some not so active ones. He drew the activeness using the arrows as edges and boxes which represented the amount of information. These results suggested that A, B, and $\mathrm{C}$ wanted to remove the gap between the experts and the novices though $\mathrm{D}$ did not point the gap. However, he said that there is a gap between the experts and the novices in his interview. From the discourse, he might not draw the width of edges intentionally. He showed that all the student-staff members and the teacher collaborate with each other but the degree of collaboration differed for each member. 
Table 5: Drawn pictures of real and ideal relationships between student-staff members

(R: Real situation, I: Ideal situation)

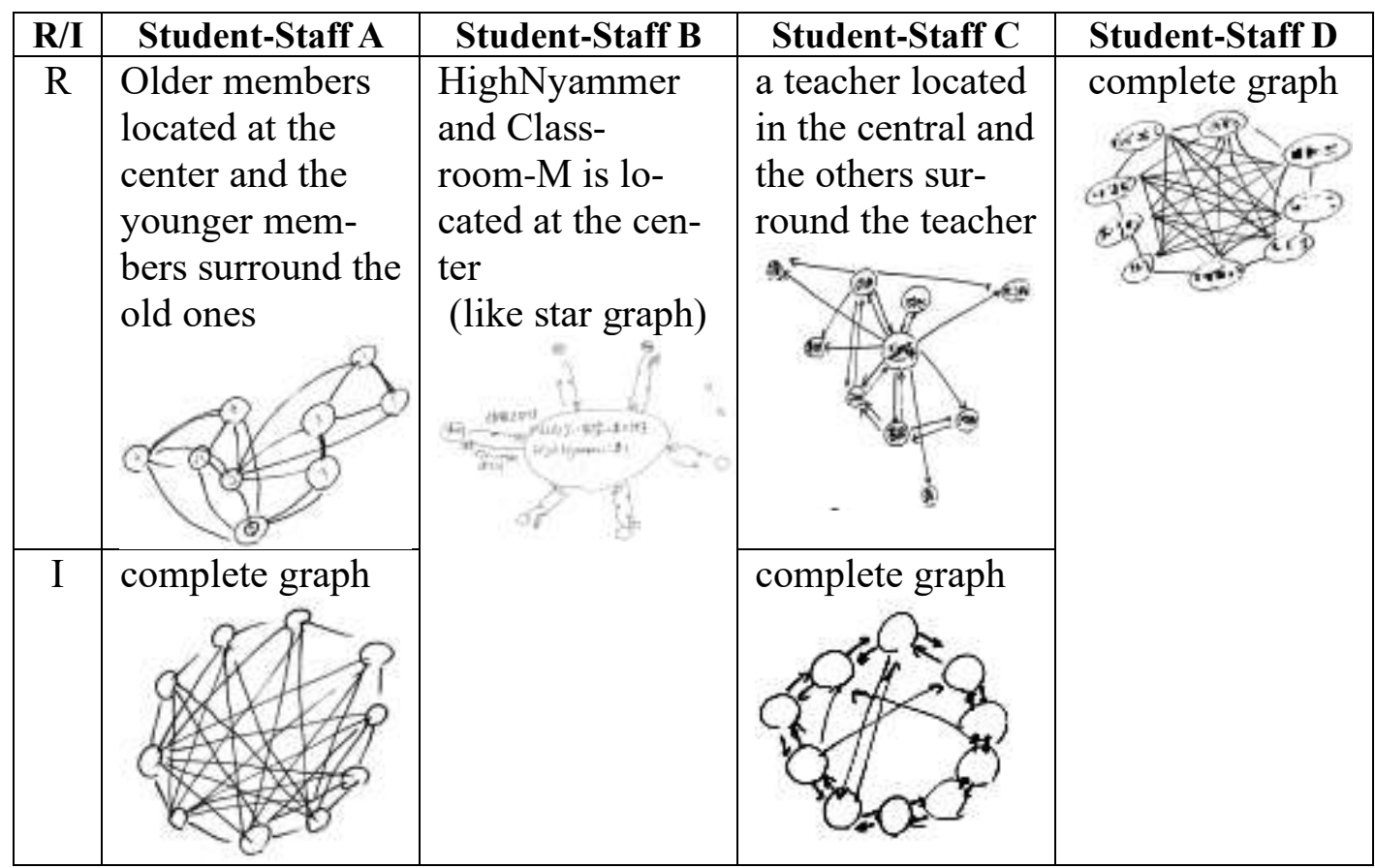

In the response to Q2, A and B said "please be interested in your colleagues' works more" as shown in Table 6. They noticed the importance of collaboration and that it helps the novice student-staff members do his/her work in Classroom-M.

Interestingly, $\mathrm{C}$ and $\mathrm{D}$ gave completely different replies from $\mathrm{A}$ and $\mathrm{B}$. Both $\mathrm{C}$ and $\mathrm{D}$ reflected their own situation of when they were novices, and D compared his own situation with his colleague's situation. He pointed the characteristics of student-staff members' community and suggested that all the members should become better gradually because the whole community of student-staff members and the teacher should continue to improve.

All the student-staff members answered that there were no inconveniences as response to Q3.

Table 6: Answers to Q2 in the interview

\begin{tabular}{|l|l|}
\hline & Answers \\
\hline A & $\begin{array}{l}\text { Please be interested in your colleagues' works. You have limited to your colleagues' } \\
\text { works now. I would say that talking with your peers helps to correct the direction of } \\
\text { your work and solve your problems. }\end{array}$ \\
\hline B & $\begin{array}{l}\text { You should be interested in your colleagues' works. I am interested in your work } \\
\text { because your works are deeply concerned with my works. It is important to show } \\
\text { your progress and tell your situation, especially "I cannot/do not understand" to us. }\end{array}$ \\
\hline C & $\begin{array}{l}\text { I don't have such kind of messages because I think I was the worst in my novice days } \\
\text { in this community. When I was a novice, I got a lot of messages from my colleagues } \\
\text { asking me about my progress because I did not report my progress for a while. These } \\
\text { messages motivated me to timely report my progress and share my concerns with my } \\
\text { colleagues. }\end{array}$ \\
\hline
\end{tabular}


\begin{tabular}{|l|l}
\hline D & You should find your own way of how to work in this community. I can tell the way to
\end{tabular} increase your value of betweenness centrality but it does not improve your quality of work; you cannot get the same output if you completely follow my way to be a kind of senior. In my community, everyone is getting better eventually. It is not limited to senior staff but also novice staff.

\section{Conclusion}

This study provided real-time feedback to improve workers' collective cognitive responsibility. For a community of workers to adapt a collaborative knowledge creation perspective, it is important to strengthen communication within the team. We hypothesized that attaining higher values of betweenness centrality in the relationship of subjects reflects improvements in the collective cognitive responsibility. Therefore, we developed a BBS that could feed back values of betweenness centrality using network-analysis methodology in real-time. The value reflects the state of distributed engagement, not mediated by supervisors such as teachers or instructors. HighNyammer revealed to workers their betweenness-centrality value in real time. We conducted a HighNyammer trial use, questionnaire surveys, and retrospective interviews with four student-staff members to examine the effectiveness of our specialized BBS; the results showed that it could be effective, especially for novice workers. Furthermore, the subjects recognized the meaning of the betweenness centrality value in relation to their own works as student-staff members. They also recognized that the meaning of betweenness centrality values depended on each student-staff member's degree of expertise in Classroom-M.

The main limitation of this research is the lack of a substantial body of data to prove that HighNyammer has a long-term impact on each student-staff member's level of collective cognitive responsibility. Similarly, the reproducibility of the results has not been confirmed, as the survey was conducted on a small sample (four student-staff members) over a short period (six months without the betweenness-centrality calculation and two months with the calculation). We will continue our trial use of HighNyammer and analyze the long-term effects of sharing betweenness-centrality values with student-staff members using quantitative method. We have planned to add new function for HighNyammer to calculate the amount of words of each post for separating simple replies from rich replies. The rich replies may contribute in creating new ideas or solutions than simple ones, thus the function has possibility to show the importance of each participant node as a student-staff community mediator better than the existing function. We will also prepare a data-collection methodology for actual working situations to compare with the data from HighNyammer. For the future, we will examine whether more adequate scaffolding methods for improving collective cognitive responsibility exist from the viewpoint of betweenness centrality.

\section{Acknowledgement}

We would like to thank The Japan Society for the Promotion of Science Kakenhi (No. 17K01136). We appreciate the student-staff members who cooperated in this research. This research is an updated version of Kondo, Tohyama, Ohsaki, and Yamada [28], which added new data, system information, and insights to the existing literature. 


\section{References}

[1] M. Scardamalia, "Collective cognitive responsibility for the advancement of knowledge," in Liberal education in a knowledge society, B. Smith Ed. Chicago, IL: Open Court, pp.6798, 2002.

[2] J. Zhang, M. Scardamalia, R. Reeve, and R. Messina, "Designs for Collective Cognitive Responsibility in Knowledge Building Communities," Journal of the Learning Sciences, vol.18, no.1, pp.7-44, April 2009.

[3] A.-L. Barab'asi, "Network theory: The emergence of the creative enterprise", Science, vol. 308, pp.639-641, April 2005.

[4] S. Strogatz, "Exploring complex network," Nature, vol. 410, pp.268-276, March 2001.

[5] J. Oshima, R. Oshima, and Y. Matsuzawa, "Knowledge Building Discourse Explorer: A social network analysis application for knowledge building discourse", Educational Technology Research and Development, vol.60, pp.903-921, October 2012.

[6] I. Claros, R. Cobos, and C. Collazos, "An Approach Based on Social Network Analysis Applied to a Collaborative Learning Experience," IEEE Transanctions on Learning Technologies, vol.9, no.2, pp.190-195, April 2016.

[7] M. Leanne, Y. Matsuzawa, and M. Scardamalia, "Rotating Leadership and Collective Responsibility in a Grade 4 Knowledge Building Classroom," International Journal of Organizational Design and Engineering, vol.4, pp. 54-84, November 2016.

[8] P. Griffin, B. McGaw, and E. Care. (Eds.), "Assessment and Teaching of 21st Century Skills,” Netherlands: Springer, 2012.

[9] OECD, "PISA 2015 collaborative problem solving framework," OECD Publishing, 2013.

[10] D. L. Schwartz, and T. Martin, "Inventing to prepare for learning the hidden efficiency of original student production in statistics instruction," Cognition \& Instruction, vol.22, pp.129-184, 2004.

[11] N. Miyake, "Conceptual change through collaboration," In Vosniadou, S. (Ed.) International Handbook of Research on Conceptual Change, New York: Routledge, pp.453-478, 2008.

[12] G. Hatano, "Toward a theory of adaptive expertise," The annual report of educational psychology in Japan, vol.40, pp.45-47, 2001. (in Japanese)

[13] G. Hatano, and K. Inagaki, "Two courses of expertise," In H. Stevenson, H. Azuma, and K. Hakuta (Eds.) Child Development and Education in Japan, New York: W. H. Freeman, pp.263-272, 1986.

[14] J. D. Bransford, A. L. Brown, and R. R. Cocking, "How People Learn: Brain, Mind, Experience, and School," Washington, D.C: National Academy Press, 2000. 
[15] M. Scardamalia, and C. Bereiter, "Computer-supported knowledge building communities," Journal of the learning sciences, vol.3, pp.265-283, 1994.

[16] L. Darling-Hammond, and J. Baratz-Snowden, "A good teacher in every classroom," San Francisco: John Wiley \& Sons, 2005.

[17] I. Nonaka, and H. Takeuchi, "The knowledge-creating company: how Japanese companies create the dynamics of innovation," New York: Oxford University Press, 1995.

[18] C. Bereiter, and M. Scardamalia, "Surpassing ourselves," Chicago, IL: Open Court, 1993.

[19] M. Scardamalia, and C. Bereiter, "Knowledge Building and Knowledge Creation," in The Cambridge Handbook of The Learning Sciecnes 2nd Edition, K. Sawyer Ed. New York: Cambridge University Press, pp.397-417, 2014.

[20] A. Csanadi, B. Eagan, I. Kollar, D. W. Shaffer, and F. Fischer, "When coding-and-counting is not enough: using epistemic network analysis (ENA) to analyze verbal data in CSCL research," International Journal of Computer-Supported Collaborative Learning, vol.13, pp.419-438, 2018.

[21] D. W. Shaffer, "Epistemic network analysis: understanding learning," In F. Fischer, C. E. Hmelo-Silver, S. R. Goldman, \& P. Reimann (Eds.), International handbook of the learning sciences, New York, NY: Routledge, pp.520-531, 2018.

[22] J. van Aalst, “Assessment in collaborative learning," In C. E. Hmelo-Silver, C. A. Chinn, C K. K. Chan \& A. O'Donnell (Eds.), The international handbook of collaborative learning, New York, NY: Routledge, pp.280-296, 2013.

[23] S. Järvelä, and A. F. Hadwin, "New Frontiers: Regulating Learning in CSCL," Educational Psychologist, vol.48, no.1, pp.25-39, January 2013.

[24] F. Vogel, and A. Weinberger, "Quantifying qualities of collaborative learning processes," In F. Fischer, C. E. Hmelo-Silver, S. R. Goldman, \& P. Reimann (Eds.), International handbook of the learning sciences, New York, NY: Routledge, pp.500-510, 2018.

[25] H. Kondo, and H. Narahara, "Design and Implementation of a Dynamic Reconfigurable Classroom for Cooperative Learning," in Conference Proceedings of the 3rd International Conference on Intelligent Networking and Collaborative Systems, pp. 328-329, December 2011.

[26] J. Oshima, Y. Niihara, K. Ota, and R. Oshima, "Collaborative Learning Processes and Individual Contribution: Discourse Analysis Based on the Network Structure of Utterances," Japan Journal of Educational Technology, pp.333-342, January 2010. (in Japanese)

[27] Neo4J. https://neo4j.com/ (visited: 2020/01/10)

[28]H. Kondo, S. Tohyama, A. Ohsaki, and M. Yamada, "HighNyammer BBS Scaffolds the Development of Each Learner's Collective Cognitive Responsibility," Proceedings of 2019 9th International Congress on Advanced Applied Informatics (IIAI-AAI), pp.184-189, July 2019. 